\title{
The study of redistribution in residual stresses during fatigue crack growth
}

\author{
M. Noghabi1 ${ }^{1}$ I. Sattari-far ${ }^{2}$ and H. Hosseini Toudeshky² \\ 1 Department of Mechanical Engineering, Amirkabir University of Technology, 15875-4413, Tehran, Iran \\ Phone: +9866405844; Fax: +9866419736 \\ 2 Department of Aerospace Engineering, Amirkabir University of Technology, 15916-34311, Tehran, Iran
}

\begin{abstract}
Numerical and experimental study was conducted on fatigue crack growth (FCG) of metallic components to investigate the redistribution of mechanical residual stresses during FCG. To this end, the compact tension specimens of an aluminium alloy were used. In addition, mechanical residual stresses were introduced near the crack tip by applying compressive and tensile loads, followed by visually observing the side-surface of the specimens to estimate the crack growth length. In the numerical simulation, cyclic J-integral was used as the crack growth fracture parameter and a good agreement was observed between the numerical and experimental results. The results of the finite element method demonstrated a clear redistribution of mechanical residual stresses during FCG. After a few cycles, the residual stress field around the crack tip reached a lower magnitude value confined in a smaller zone, although this zone was stable during the remaining fatigue process. Finally, present study evaluated the effect of stress ratio, load amplitude, and initial residual stresses level on the redistribution of residual stresses. It was observed that the residual stresses are mainly released during the first steps of fatigue loading.
\end{abstract}

ARTICLE HISTORY

Received: $18^{\text {th }}$ Jan. 2021

Revised: $10^{\text {th }}$ Aug. 2021

Accepted: $16^{\text {th }}$ Nov. 2021

\section{KEYWORDS}

Fatigue crack growth;

J-integral;

residual stress;

relaxation.

\section{INTRODUCTION}

Acceptable fatigue life assessment of components is desirable for various industries and mechanical residual stresses play a significant role in this issue. It is well-known that the fatigue life reduces in the tensile residual stress field since it increases the fatigue crack growth (FCG) rate while compressive residual stresses decrease the growth rate of the crack [1].

During the last decades, several studies have evaluated the effects of residual stresses on FCG rates. For instance, Vaidya et al. [2] studied the effect of welding residual stresses on fatigue crack propagation in a butt joint of an aluminium alloy and found that the generation of tensile residual stresses near a notch tip leads to faster fatigue crack propagation than that in the base materials. Larue and Daniewicz [3] predicted the FCG in the presence of residual stresses using the superposition rule and closure-based approach. They found that increased accuracy can be obtained using a closure-based approach. In another study, Servetti and Zhang [4] focused on the distribution of residual stresses at a crack tip by finite element method (FEM) using the effective stress ratio (R) for accounting for the residual stress effects. Their result indicated how crack propagation is affected by residual stresses. Further, Ghidini and Donne [5] demonstrated the possibility of using fracture mechanics to predict the fatigue life of structures in the presence of residual stresses and variable amplitude loading conditions. They developed a simple engineering approach that provides a practical and reliable basis for the analysis of structures in the presence of a residual stress (RS) field. Bussu and Irving [6] conducted a study regarding the effects of welding residual stress zone on the fatigue propagation of the cracks both parallel and orthogonal to the weld direction. They concluded that the crack growth behavior in the friction stir welded joints was greatly influenced by the welding residual stresses while the structure and hardness changes had a minor influence in this regard. Furthermore, Jacob et al. [7] performing an experimental and numerical study on the effects of residual stresses on the FCG behavior of S355 steel weldments, found that the residual stresses play a pivotal role in the fatigue life of the welded structures, especially in the near-threshold region.

Two common methods are available for calculating the FCG rates in residual stress fields, one of which employs the superposition rule to determine the effective stress ratio [8]. The other method, originally proposed by Elber [9], is based on the crack closure concept. This method calculates the crack opening stress intensity factor and then the effective stress intensity factor range is obtained in a combined stress field of the applied force and residual stresses [10]. The validity of both methods is generally accepted [4]. Farrahi et al. [11] presented crack propagation tests using compact tension (CT) specimens to evaluate the effects of the residual stress field resulting from shot peening and the indentation technique on the crack growth behavior. Based on the results, compressive residual stresses delayed crack propagation. Semari et al. [12] studied the effect of residual stresses obtained by the cold expansion process on the crack growth in an aluminium alloy. They found that compressive residual stresses near the crack tip reduce the effect of the applied stress field and have a tendency to decrease the crack growth rate. Gozin et al. [13] investigated the effect of the compressive residual stress field on the FCG from a hole using 3D FEM and PICC methods. Their results showed that applying the modified 
PICC method reduces the 3D FEM fatigue life prediction errors. Ren et al. [14] demonstrated that laser shock processing had an important influence on the fatigue performance of an aluminium alloy.

It is known that the initial induced residual stresses are relaxed during the component operating life. Furthermore, the relaxation phenomenon is significantly crucial in designing a component [15]. Zhu et al. [16] evaluated the change of residual stress distribution during fatigue crack propagation and established an analysis approach for the change in the residual stress distribution. They found that neglecting the relaxation of residual stresses would overestimate the crack propagation rate and gives a more conservative result. Yi et al. [17] studied the relaxation of welding residual stresses under fatigue loading and found that residual stresses are relaxed in the early repeated loads. In another study, Lee et al. [18] investigated the residual stress relaxation of the steel butt welds under cyclic loading using FEM. They developed an analytical method to evaluate the residual stress relaxation in butt welds submitted to cyclic mechanical loading. Xie et al. [19] developed a model to predict the relaxation of welding residual stresses by cyclic loading. Their analytical model considered the effects of the initial residual stress, yield stress, stress amplitude, and the number of cycles to predict the relaxation of the welding residual stresses. They found that considerable residual stresses are released during the first few cycles. Farajian and coworkers [20] studied the relaxation of welding residual stresses under cyclic loading by means of X-ray method. Their results showed that the relaxation of residual stresses takes place at the first loading cycle when the Von Mises stress exceeds than the monotonic yield strength of the base metal. Dattoma et al. [21] conducted a numerical simulation to study the relaxation of welding residual stresses by cyclic loading. They found that initial residual stresses significantly are reduced after the first cycles of loading. Jiang et al. [22] studied residual stress change around fatigue crack tips in CT specimens. They found that the residual stresses at the crack tip are correlated to the static load magnitude. Yonezawa et al. [23] investigated the effects of cyclic loading on the residual stress relaxation, and estimated the fatigue life of steel joints considering residual stresses. Zhong et al. [24] studied the relaxation of welding residual stresses under constant and variable amplitudes cyclic loading, considering effects of stress ratio and material yield stress on residual stress relaxation. Ghaderi and coworkers [25] carried out a numerical and experimental investigation to study the effective parameters on residual stress relaxation in welded aluminum plates under cyclic loading. They found that residual stress relaxation is affected by stress amplitude, mean stress, initial residual stress, and number of cycles.

Although several studies have addressed the effects of residual stresses on the FCG, only a limited number have considered the relaxation of initial residual stresses during the FCG. Therefore, it is interesting to study the residual stress relaxation and its influence on the fatigue life of the engineering structures. The present study addresses residual stress relaxation during the FCG, following by estimating the crack propagation rate by considering residual stress relaxation. Further, parameters such as inducing residual stresses, relaxation during the fatigue growth, and fatigue life estimation were simulated by the commercial finite element software ABAQUS [26]. Experimental studies were also conducted to verify the FEM results.

\section{THEORETICAL ASPECTS}

\section{Residual Stresses}

Residual stresses are typically defined as the self-equilibrating stresses which remain in mechanical parts after removing the original cause of the stresses. Such stresses are induced where a stress gradient exists in a body and the cause of stresses are larger than the elastic limit. These stresses can be generated following manufacturing processes, fabrication or assembly [27].

Stresses are classified as either 'primary' or 'secondary' based on structural integrity assessment procedures. Primary stresses are not self-equilibrating and have a net force or bending moment on a section. Conversely, secondary stresses are self-equilibrating and the net force and bending moment across a section equal to zero [28]. Based on these definitions, the residual stresses should be considered as secondary stresses. According to [29], residual stresses may be determined analytically, numerically, or from experimental measurements (e.g., destructive, semi-destructive, or nondestructive methods).

The methods that have been employed to generate residual stresses within samples in a controlled manner can be divided into mechanical and thermo-mechanical methods. Thermo-mechanical methods include welding and quenching samples. Mechanical methods include plastic deformation of a bending beam, shrink fit plug, side punching of a compact tension (CT) specimen and in-plane compression or tension of a specimen [30]. Figure 1 shows an example of introducing residual stresses by in-plane compression of a CT specimen.

In the present study, residual stresses were mechanically induced in CT specimens to avoid metallurgical changes in the material. 

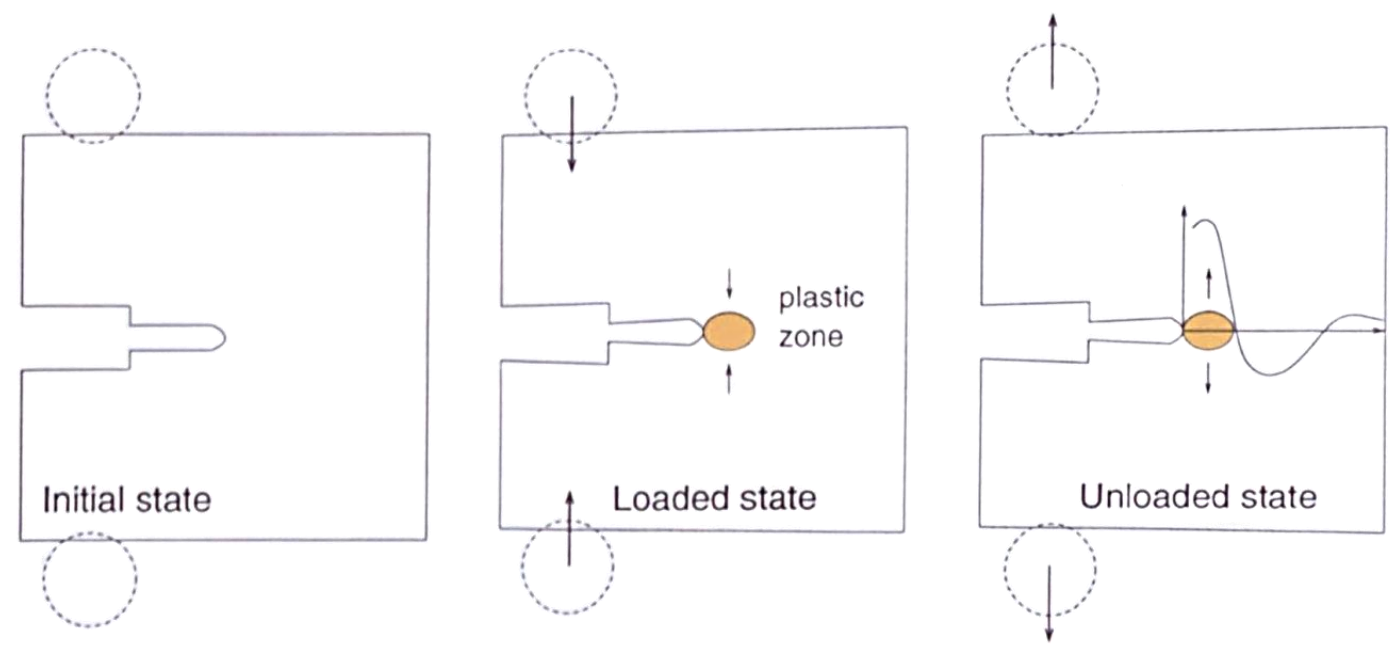

Figure 1. Introducing a residual stress field by in-plane compression [30]

\section{Modification of the J-integral in the Presence of Residual Stresses}

Rice [31] first presented the idea of the J-integral, having the following equation form.

where,

$$
J=\int_{\Gamma}\left(W \delta_{1 \mathrm{i}}-\sigma_{i j} \frac{\partial u_{j}}{\partial x_{1}}\right) n_{i} d S
$$

$$
W=\int_{0}^{\varepsilon_{i j}^{m}} \sigma_{i j} d \varepsilon_{i j}^{m}
$$

In these equations, $\mathrm{W}, n_{\mathrm{i}}, \sigma_{i j}$, and $u_{j}$ represent the strain energy density, the component of the unit normal $x_{1}$ over contour $\Gamma$ (i.e., a contour surrounding the crack-tip in the counterclockwise direction), the applied force, and the displacement component, respectively. In the case of combined primary and secondary stresses, the crack tip is subjected to nonproportional loading due to the substantial changes in the loading direction during the loading cycles. This affects the path-independency of the J-integral.

Furthermore, the effect of the local unloading of the plate material becomes less than that of the severe singular domains of stresses and strains in the regions which are extremely close to the crack tip. Therefore, the combined effects of residual stresses and external loads on the neighborhood of the crack tip can be effectively felt farther away from the crack tip. The use of a relatively finer mesh at the crack tip in the finite element model can somehow decrease the pathdependency of the J-integral although this substantially increases the computational load.

Lei et al. [32] presented a path-independent J-integral which could be used in problems concerning the cracks subjected to primary and secondary stresses including thermal stresses, residual stresses, or a combination of these two stresses. They further considered residual stresses as a problem of the initial strain. Additionally, they applied an average amount of residual stresses, as a distribution of the input stress, to a crack-free body and obtained the relevant strain domain of $\varepsilon_{i j}^{0}$ after separating the elastic strains. Considering the primary strains, the total strain $\varepsilon_{i j}$ is divided into two strains resulting from mechanical loading $\varepsilon_{i j}^{m}$ and initial strain $\varepsilon_{i j}^{0}$ as follows:

$$
\varepsilon_{i j}=\varepsilon_{i j}^{\mathrm{m}}+\varepsilon_{i j}^{0}
$$

The initial strains are only dependent on plastic strains in the initial state $\left.\varepsilon_{i j}^{p}\right|_{\text {initial }}$, as the initial elastic strains $\varepsilon_{i j}^{\mathrm{e}}$ are recoverable after unloading.

$$
\varepsilon_{i j}^{0}=\left.\varepsilon_{i j}^{p}\right|_{\text {initial }}
$$

This is because the initial elastic strains are reversible, which makes them a part of the mechanical strains.

The strain energy density $\mathrm{W}$ is considered as another important point to consider when computing the J-integral in the cases in which residual stresses are present. More importantly, W should only rely on mechanical strains instead of the initial strains. The mechanical strain energy density was modified as follows:

$$
W^{m}=W-\left.W^{p}\right|_{\text {initial }}
$$


where, $W^{m}, \mathrm{~W}$, and $\left.W^{p}\right|_{\text {initial }}$ are the mechanical strain energy density, the total strain energy density, and the initial plastic strain energy density, respectively. Given the initial strain case, the equation is expressed as:

$$
J=\int_{A}\left[\left(\sigma_{i j} \frac{\partial u_{j}}{\partial x_{1}}-W^{m} \delta_{1 i}\right) \frac{\partial q_{1}}{\partial x_{i}}+\left(\sigma_{i j} \frac{\partial \varepsilon_{i j}}{\partial x_{1}}-\frac{\partial W^{m}}{\partial x_{1}}\right) q_{1}\right] d A
$$

Where $q_{1}$ is an arbitrary smooth function in the $x_{1}$-direction.

In the finite element form, the expression $\frac{\partial w}{\partial x_{1}}$ is directly incomputable. The elastic-plastic J-integral in Eq. (6) turns into a nonlinear elastic equality by using the elastic equation of $\mathrm{W}$ and the chain derivative law as follows.

$$
\frac{\partial W^{m}}{\partial x_{1}}=\frac{\partial W^{m}}{\partial \varepsilon_{i j}^{m}} \frac{\partial \varepsilon_{i j}^{m}}{\partial x_{1}}=\sigma_{i j} \frac{\partial \varepsilon_{i j}^{m}}{\partial x_{1}}=\sigma_{i j} \frac{\partial \varepsilon_{i j}}{\partial x_{1}}-\sigma_{i j} \frac{\partial \varepsilon_{i j}^{0}}{\partial x_{1}}
$$

Finally, Eq. (8) is obtained by substituting Eq. (7) into (6) as follows:

$$
J=\int_{A}\left[\left(\sigma_{i j} \frac{\partial u_{j}}{\partial x_{1}}-W^{m} \delta_{1 i}\right) \frac{\partial q_{1}}{\partial x_{i}}+\sigma_{i j} \frac{\partial \varepsilon_{i j}^{0}}{\partial x_{1}} q_{1}\right] d A
$$

In this form, the $\mathrm{J}$-integral turns into finite element post-processors for computing the $\mathrm{J}$ values for the cracks in residual stress domains.

\section{Fatigue Crack Growth Model Based on the J-integral Approach}

Considering the large plastic regions created at the crack tip due to the presence of residual stresses, elastoplastic fracture mechanics ( $J$-integral) can provide a better understanding of the crack growth mechanism. This approach is expressed as follows [33]:

$$
\Delta J=\Delta J_{e l}+\Delta J_{p l}=\frac{(\Delta K)^{2}}{E^{\prime}}+\frac{\eta \Delta A_{p l}}{B b_{0}}
$$

Where, $b_{0}$ and $B$ are the initial ligament of the specimen and the net thickness of the specimen. In addition, $A_{P l}$ and $\eta$ indicate the area under the load-displacement curve and a non-dimensional coefficient, which is obtained from Eq. (10) for the evaluated specimen in the present study.

$$
\eta=2+0.522 \frac{b_{0}}{W}
$$

In Eq. (10), $W$ denotes the effective width of the specimen.

In the present study, the adapted form of the Paris equation, based on the $J$-integral and developed by Dawling [34], was used to express the crack propagation law:

$$
\frac{d a}{d N}=C(\Delta J)^{m}
$$

In Eq. (11), $C$ and $m$ are material-dependent parameters, which are obtained experimentally. The fatigue life of the specimen during the time between the initial crack length $a_{i}$ and final crack length $a_{f}$ can be determined by integrating Eq. (11). A crack is propagated discontinuously in the finite element simulation thus this integration turns into a summation of terms and is written as Eq. (12):

$$
\mathrm{N}=\sum_{\mathrm{i}=\mathrm{a}_{\mathrm{i}}}^{\mathrm{a}_{\mathrm{f}}} \frac{\mathrm{da}}{\mathrm{C}(\Delta \mathrm{J})^{\mathrm{m}}}
$$

It is worth noting that ' $d a$ ' is the amount of the crack growth at each step in FEM calculations, which can be equal to the element length in the region adjacent to the crack tip.

\section{EXPERIMENTAL STUDIES}

This section describes the preparation of compact tension (CT) specimens and introduces mechanical residual stresses and fatigue crack growth tests. The material characterizations of the aluminium alloy are provided as well. These properties are required as the input values for numerical simulations. 


\section{Material Properties}

The material is $8.4 \mathrm{~mm}$ thickness 5000 series Al Alloy with mechanical properties given in Table 1 . The tensile test specimens were prepared according to the ASTM E8-00 standard. The dimensions of these specimens are shown in Figure 2 three specimens were used to obtain the mechanical properties of Al alloy at room temperature. Further, the ASTM E647 standard was followed to prepare the CT specimens [35]. The tested CT specimens were prepared by the wire-cut process with the dimensions given in Figure 3.

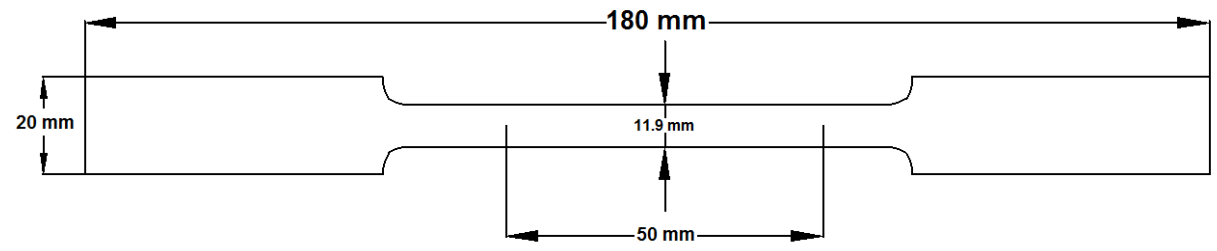

Figure 2. The dimensions of the tensile test specimens
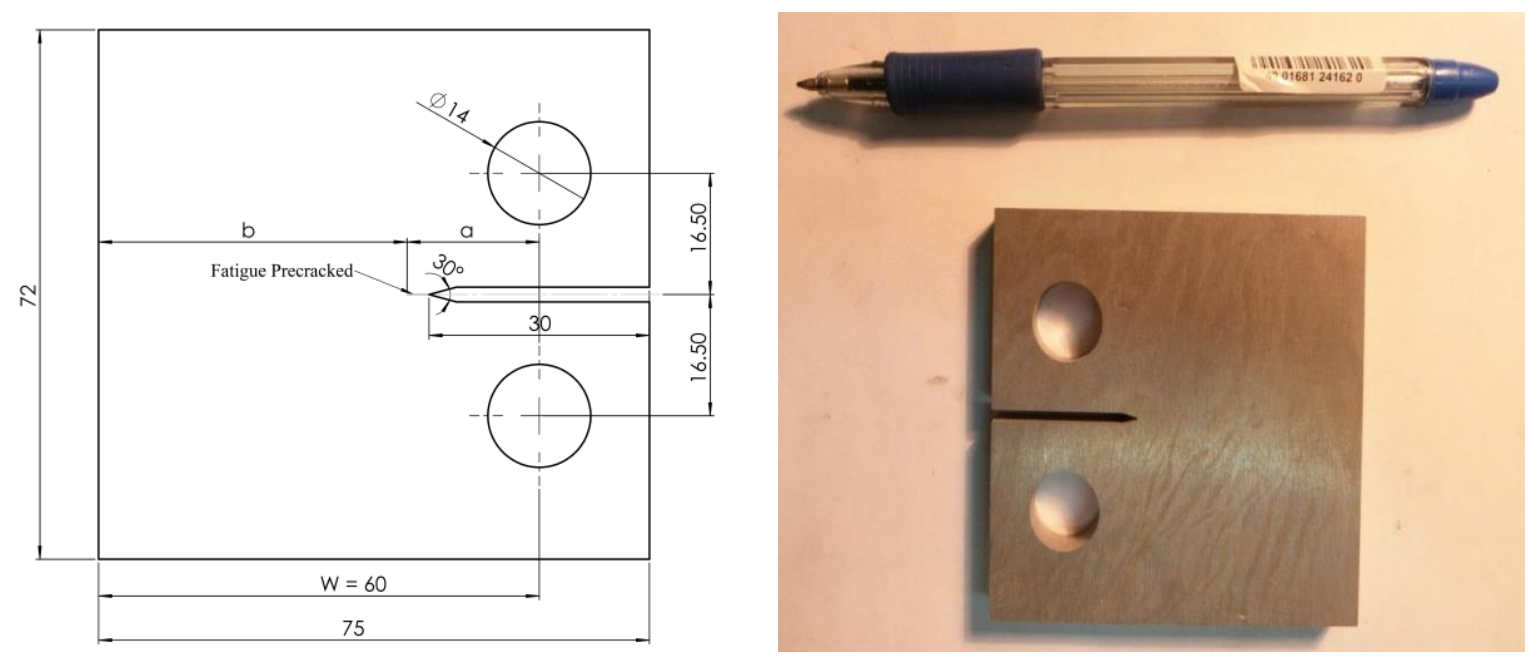

Figure 3. The CT specimen configuration

Table 1. Mechanical properties of 5000-series aluminium alloy

\begin{tabular}{cccc}
\hline $\begin{array}{c}\text { Young' s Modulus } \boldsymbol{E} \\
(\text { GPa })\end{array}$ & Poisson's Ratio $\boldsymbol{v}$ & Yield Stress $\boldsymbol{\sigma}_{\boldsymbol{y}}(\mathbf{M P a})$ & $\begin{array}{c}\text { Ultimate Strength } \boldsymbol{\sigma}_{\boldsymbol{u}} \\
(\mathbf{M P a})\end{array}$ \\
\hline 70 & 0.3 & 200 & 350 \\
\hline
\end{tabular}

\section{Inducing Residual Stress Field}

The compressive and tensile loading of the pins were used to create tensile and compressive residual stress fields near the crack tip in the CT specimens. Upon unloading, tensile residual stresses are produced around the notch root balanced by compressive stresses elsewhere if the CT specimen is subjected to a compressive load to induce plastic deformation at the notch tip [36]. This procedure was performed after fatigue pre-cracking in the specimens.

The creation of residual stresses and size of plastic zone ahead of the crack tip in CT specimens are investigated by Paul [37-39]. He used FEM to investigate the shape and size of monotonic and cyclic plastic zone in front of crack head in different conditions in CT specimens.

\section{Fatigue Tests Procedure}

All fatigue tests were conducted according to the ASTM E647 standard in the air at room temperature by a suitable fixture. As shown in Figure 4, a three mm pre-crack is grown in all CT specimens. The limit load was obtained by introducing the tensile static load after pre-cracking and the critical load was obtained to be approximately $16.5 \mathrm{kN}$. According to [40], the result represented good agreement with the limit load obtained by Eq. (13).

$$
P_{L}=1.072 \eta B b \sigma_{Y}
$$


where, $\eta=\sqrt{\left(\frac{2 a}{b}\right)^{2}+\frac{4 a}{b}+2}-\left(\frac{2 a}{b}+1\right)$.

Parameters $a$ and $b$ are represented in Figure 3, and parameter $B$ is the CT specimen thickness.

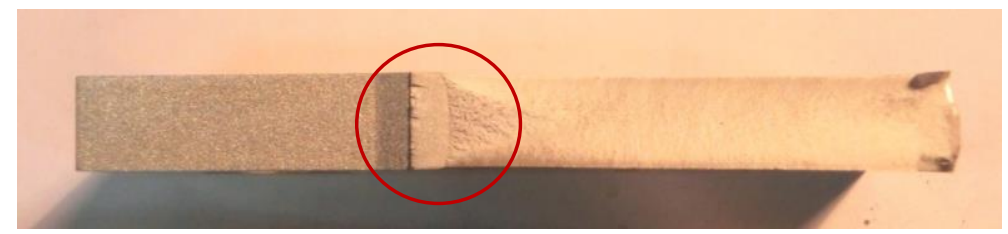

Figure 4. Induced fatigue pre-crack

All fatigue tests were conducted at a frequency of $10 \mathrm{~Hz}$, a stress ratio of 0.1 with different load ranges (i.e., $\Delta \mathrm{P}=3.6$ $\mathrm{kN}, \Delta \mathrm{P}=5.4 \mathrm{kN}$, and $\Delta \mathrm{P}=7.2 \mathrm{kN}$ ). The fatigue tests were performed by a suitable fixture as shown in Figure 5 . For estimating the amount of the crack growth during the test, the common techniques are the visual observation, the compliance method and the potential drop method [41]. In this study, the visual observation method is used for this purpose.

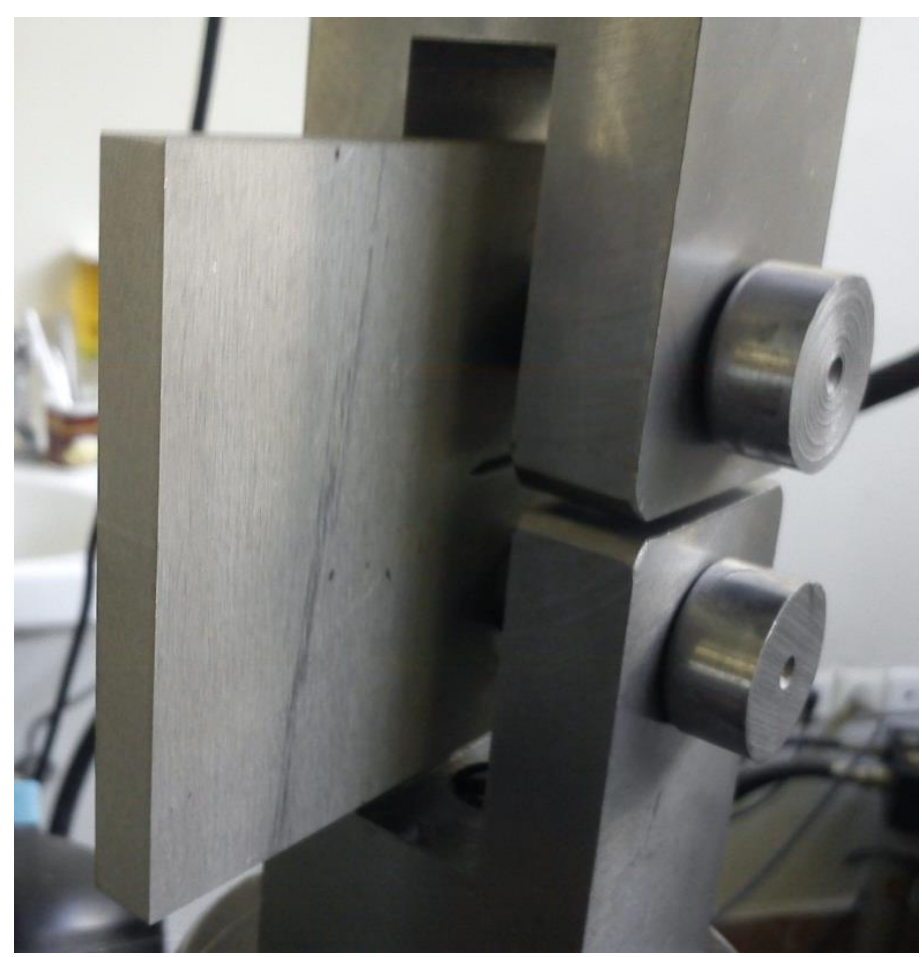

Figure 5. The fixture for fatigue testing of the CT specimens

\section{FINITE ELEMENT MODELING}

This section presents the numerical analysis which was used to estimate induced residual stresses, as well as the redistribution of residual stresses during the fatigue crack growth (FCG) and its effect on the FCG rate. The commercial finite element software ABAQUS was utilized to simulate the experiments.

\section{Geometry and Material Model}

In this study, the 2D plane strain FEM was applied to a 5000-series aluminium alloy, considering elastic-plastic material behavior. The von Mises criterion was used to identify the yield surface and isotropic hardening was assumed. Neglecting the kinematic hardening would cause the predictions to slightly overestimate the fatigue life of specimens [13]. Figure 3 illustrates the geometry of the modeled compact tension (CT) specimen. The stress - true strain curve used in this analysis was obtained from the test results of 5000-series aluminium alloy is shown in Figure 6 For convenience and time saving, only one half of the CT specimen was modeled and the symmetry condition was applied on the centerline of the specimen as well. 


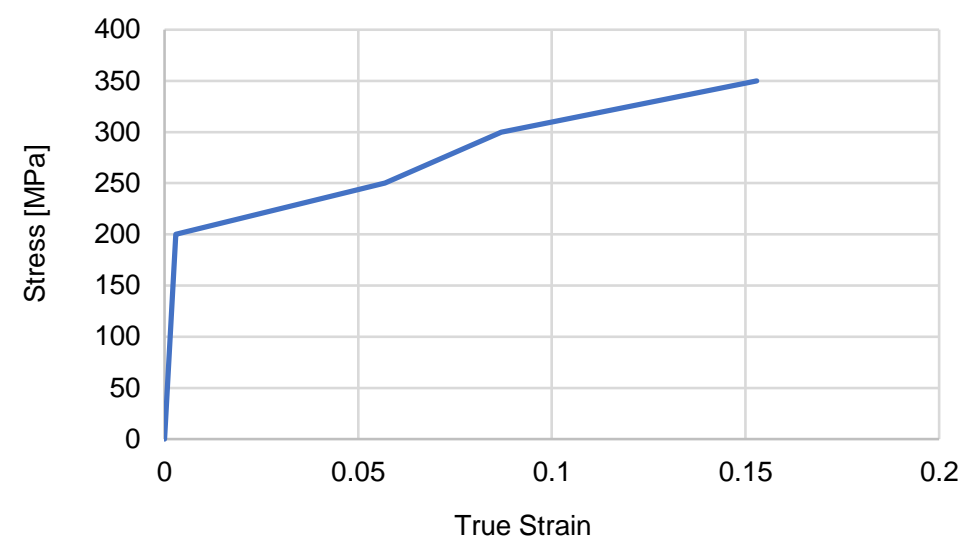

Figure 6. Stress - true strain relation used in finite element method

\section{Mesh and Boundary Conditions}

The mesh for finite element simulations is displayed in Figure 7. The mesh was created by an increasing level of refinement toward the crack tip region and the mesh sensitivity was analyzed to obtain the appropriate mesh size. The FE simulations were done using both 4-node isoparametric plane strain quadrilateral with reduced integration (CPE4R) and 8-node isoparametric plane strain quadrilateral with reduced integration (CPE8R). The results showed that there is little difference between the two cases. So, for time saving, the CPE4R element was applied as the element in the FEA model. Additionally, the element size around the crack tip was about $10 \mu \mathrm{m}$ and the numbers of elements and nodes in each model were 120627 and 121009, respectively. In addition, the simulations were made under constant loadings and fixed boundary conditions as those which were applied during the fatigue tests.

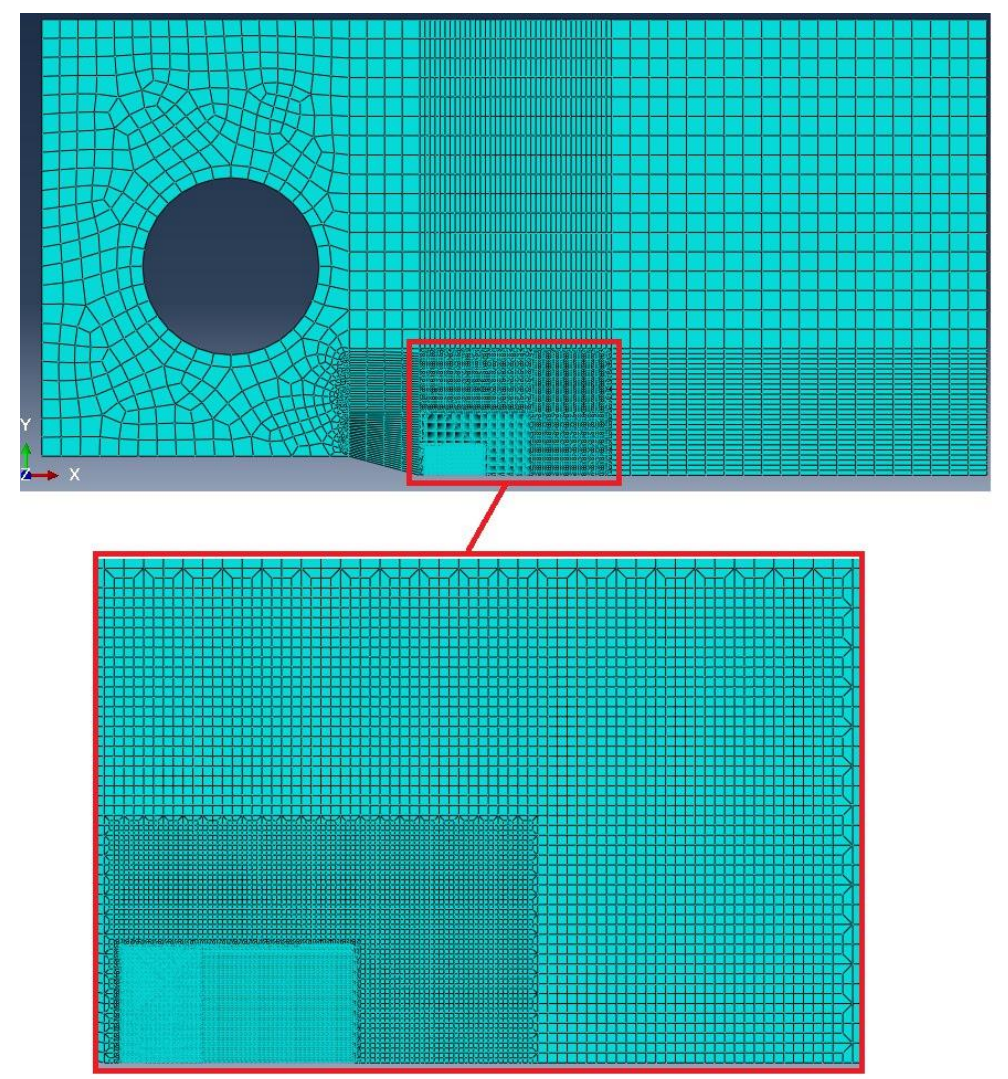

Figure 7. The finite element model of the CT specimen

\section{Modeling of Mechanical Residual Stresses}

The compressive and tensile preloads $\left(F_{i}\right)$ were applied to the specimens in order to create tensile and compressive mechanical residual stresses around the crack tip, respectively. Loading was applied in four different levels (i.e., 0.5, 0.6, 0.7 , and 0.8 ) of the limit load $\left(P_{L}\right)$ of the cracked specimen for both compressive and tensile loads. The preload was 
applied to the specimens after pre-cracking the specimens. The initial residual stresses versus the distance from the crack tip after unloading the compressive force are shown in Figure 8. Tensile residual stresses are created near the crack tip.

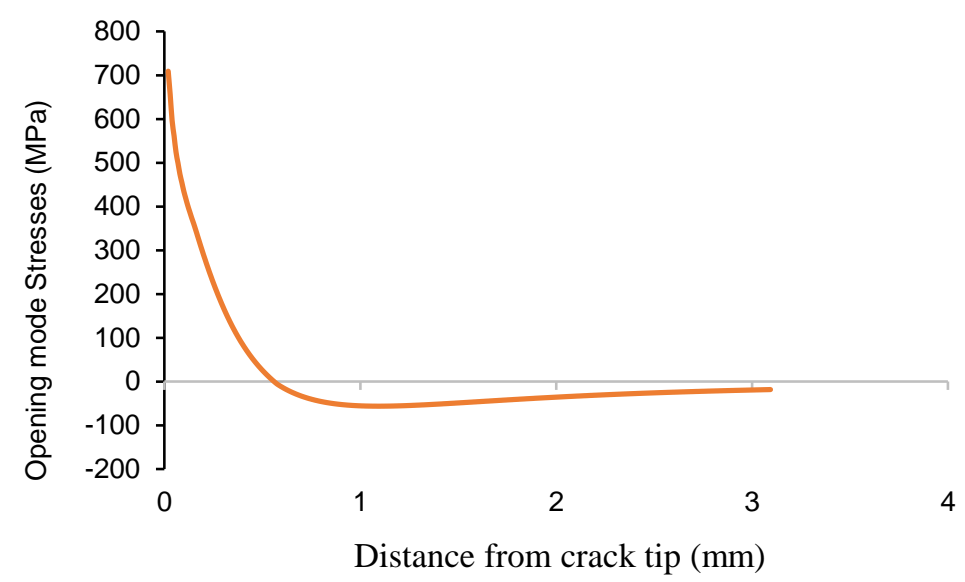

Figure 8. Initial residual stresses created in the specimen $\left(\mathrm{Fi}=0.8 \mathrm{P}_{\mathrm{L}}\right)$

\section{Crack Growth Modeling}

The node release is considered a common technique for modeling crack growth in finite element simulations. This method is simple and reliable and the node release scheme may be performed at the minimum or maximum load [42]. Solanki et al. [43] proposed the release of the node at the minimum load in order to avoid numerical disturbances due to a sudden change in crack displacement. In the present study, node release was performed in every two load cycles at the minimum load, followed by studying the effects of fatigue loading and crack growth steps on initial residual stresses.

Figure 9 displays the changes of tensile residual stresses based on the crack growth without external loading. The residual stresses near the crack tip are released significantly in few crack growth steps. The residual stresses are stabilized to a certain level after a few numbers of steps.

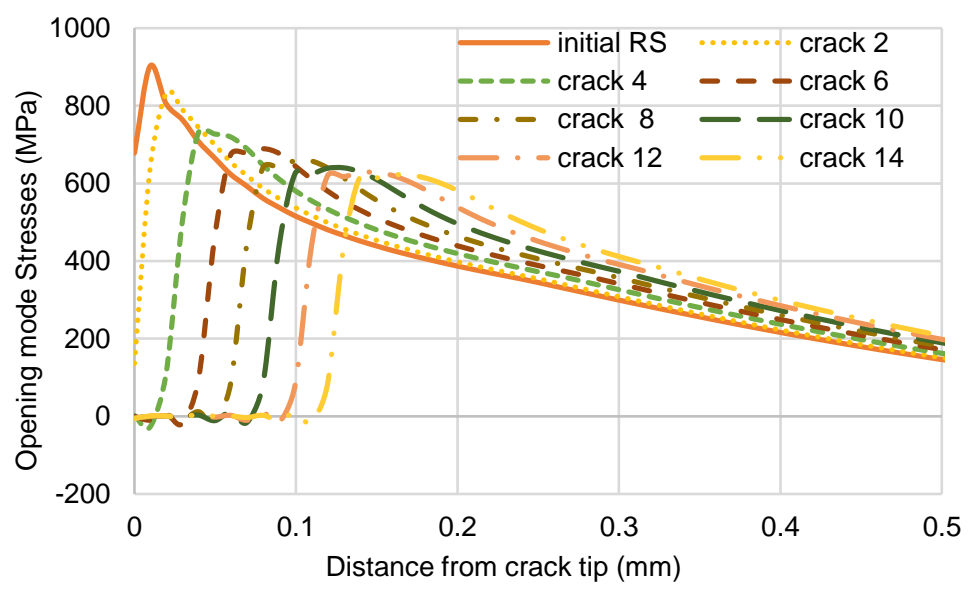

Figure 9. Redistribution of tensile residual stresses during the crack growth without external loading

The redistribution of tensile residual stresses after 15 cycles without the crack growth is shown in Figure 10. As reported by [15], the residual stresses in the specimen are relaxed after the first cycle. The stabilization level relies on the load amplitude, stress ratio, and the initial residual stress level and is discussed in the next section. 


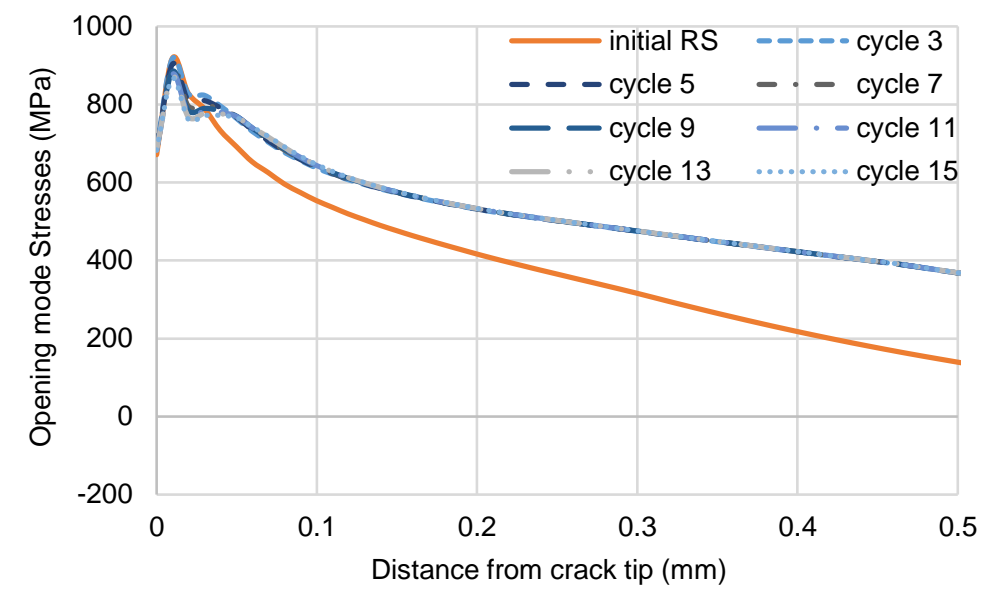

Figure 10. Redistribution of tensile residual stresses in cyclic loading without the crack growth

\section{RESULTS AND DISCUSSION}

As discussed earlier, the stabilization level relies on load amplitude, stress ratio, and initial residual stress level, which are addressed in this section.

\section{Effect of Stress Ratio (R)}

Figure 11 depicts the opening stress change by a change in the stress ratio during fatigue loading. As shown, stress relaxation fails to occur when the stress ratio is negative. In the case of negative stress ratio, fatigue loading would cause the generation of tensile residual stresses when the loading is compressive. In the cases of positive stress ratio, the initial residual stresses are relaxed in a few cycles of loading. The greater values of stress ratio lead to more relaxation of initial residual stresses. Paul [39] investigated the nature of cyclic plastic deformation on a fatigue crack tip. He found that when the maximum stress intensity factor is constant, the size of cyclic plastic zone ahead of the crack tip is increased with negetive R ratio. The result presented in Figure 9 is in agreement with [39]. Zhong et al. [24] observed the similar results.

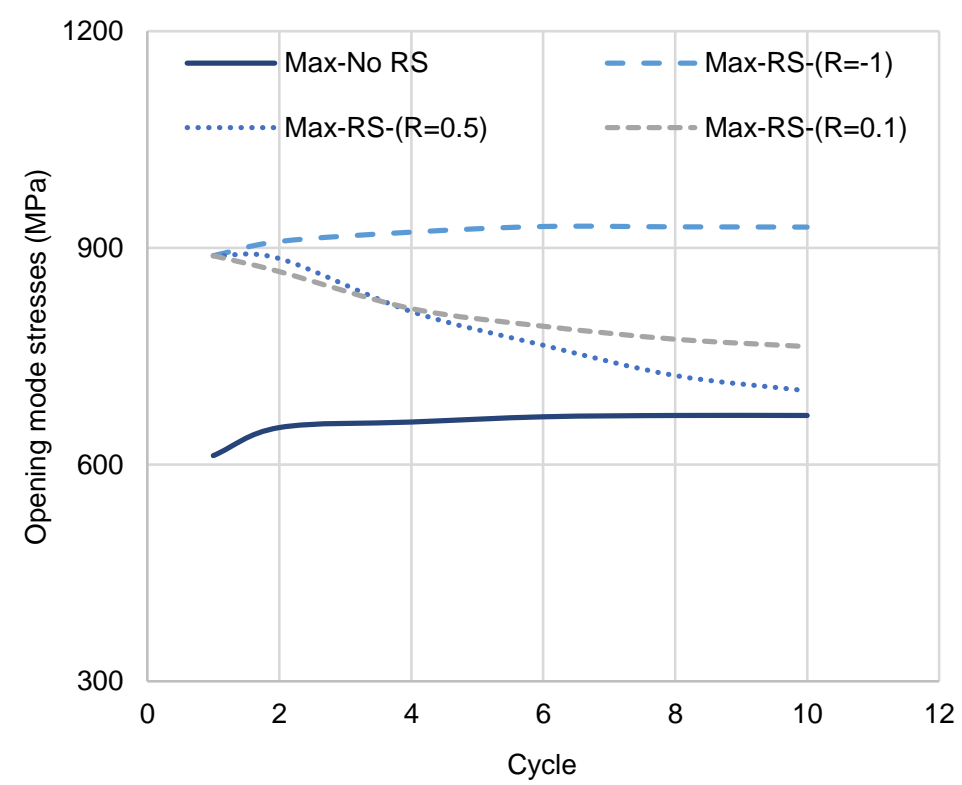

Figure 11. Opening stresses versus cycles of loading $(\mathrm{Fi}=0.6 \mathrm{PL}, \mathrm{Pmax}=4 \mathrm{kN})$

\section{Effect of Load Amplitude}

The opening stress change with the change of the maximum applied force $\left(P_{\max }\right)$ during the fatigue loading is illustrated in Figure 12, Figure 13, and Figure 14. In these simulations, the initial residual stresses and stress ratio are constant while load amplitude demonstrates a change. The opening stresses continue to decrease by increasing the cycles. However, the opening stresses reach a stable value after several cycles. The reduction percent of initial tensile residual stresses decreases when the applied stress amplitude represents an increase. It is because it produces residual stresses in the crack front when the load amplitude indicates an increase. Contrarily, the reduction percent of initial compressive residual stresses reduces when increasing the applied stress amplitude. This is because the stress magnitude at the crack 
front exceeds the yield strength as the load amplitude increases and the residual stresses are relaxed after the unloading. These results are in good agreement with the results obtained in [24] and [25].

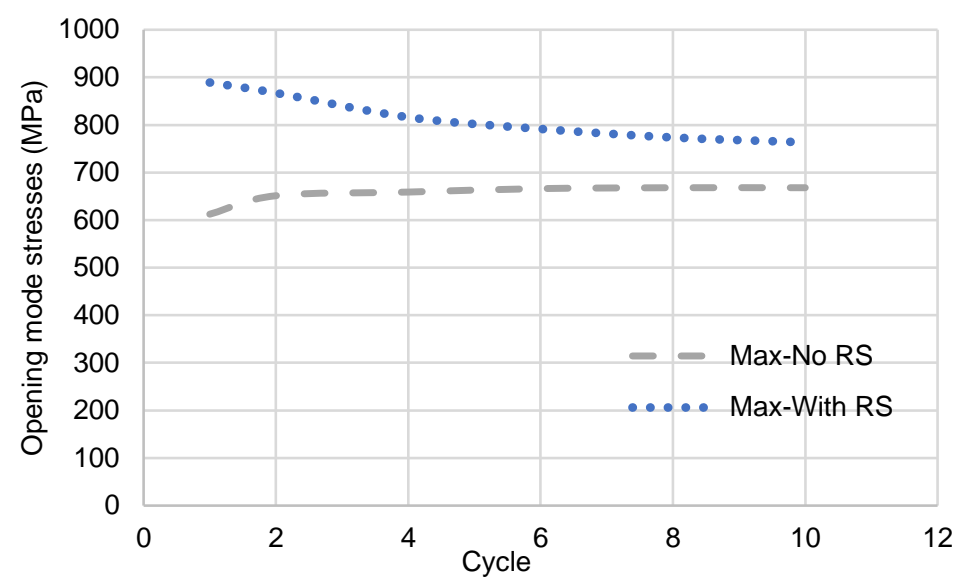

Figure 12. Opening mode stresses versus the cycles of loading $(\mathrm{Fi}=0.6 \mathrm{PL}, \mathrm{Pmax}=4 \mathrm{kN}, \mathrm{R}=0.1)$

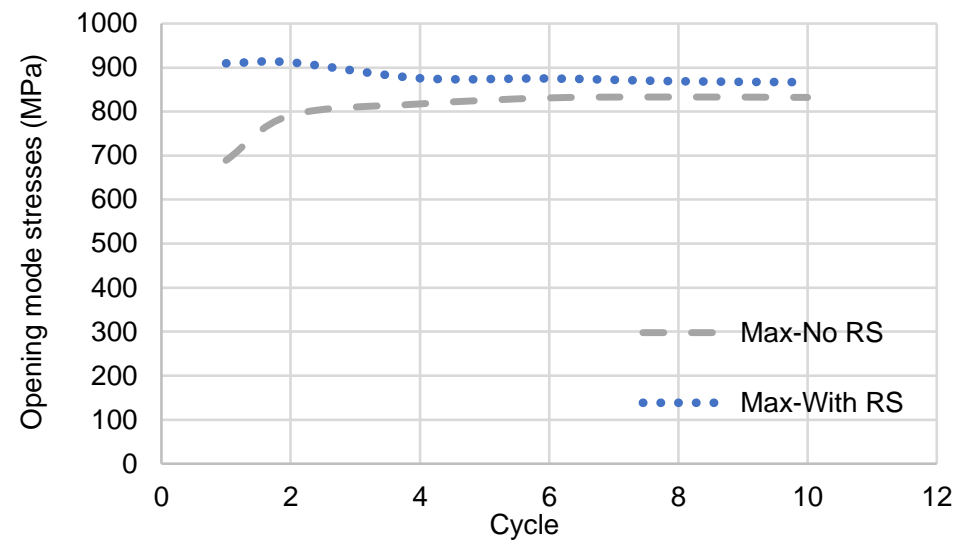

Figure 13. Opening mode stresses versus cycles of loading $(\mathrm{Fi}=0.6 \mathrm{PL}, \mathrm{Pmax}=6 \mathrm{kN}, \mathrm{R}=0.1)$

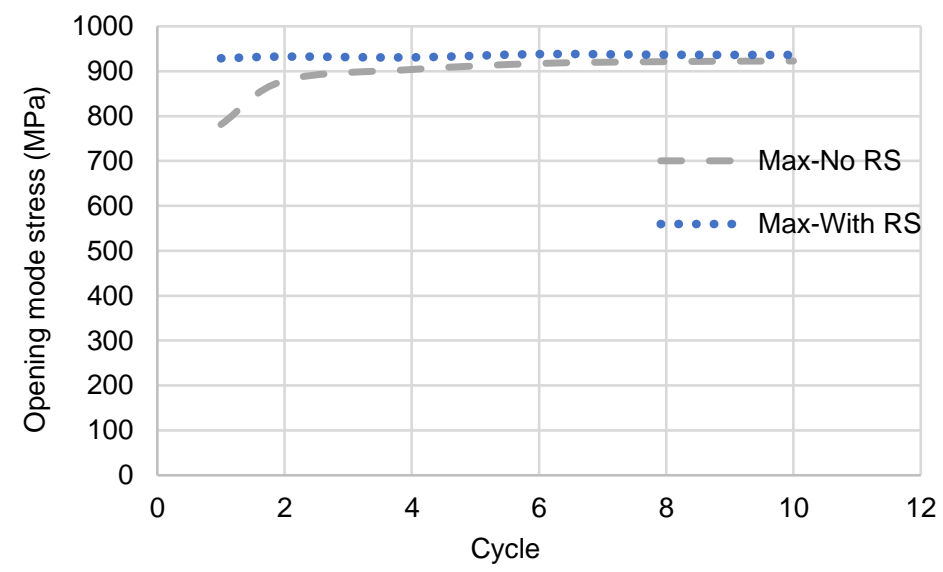

Figure 14. Opening mode stresses versus the cycles of loading $(\mathrm{Fi}=0.6 \mathrm{PL}, \mathrm{Pmax}=8 \mathrm{kN}, \mathrm{R}=0.1)$

\section{Effect of Initial Residual Stress Level}

Figure 15 depicts the effect of the initial residual stress level on the redistribution of residual stresses. Four levels of preload $\left(F_{i}\right)$ (i.e., 0.5, 0.6, 0.7, and 0.8) of the limit load $\left(P_{L}\right)$ are applied and load amplitude $\left(P_{\max }\right)$ and stress ratio $(R)$ are $4 \mathrm{kN}$ and 0.1 in all simulations, respectively. As shown, the remaining residual stresses after the relaxation have a greater value when the initial residual stresses are greater while the percentage of reducing residual stresses after load cycling is nearly equal (about 12-15\%). These results are in good agreement with the results obtained in [25]. 


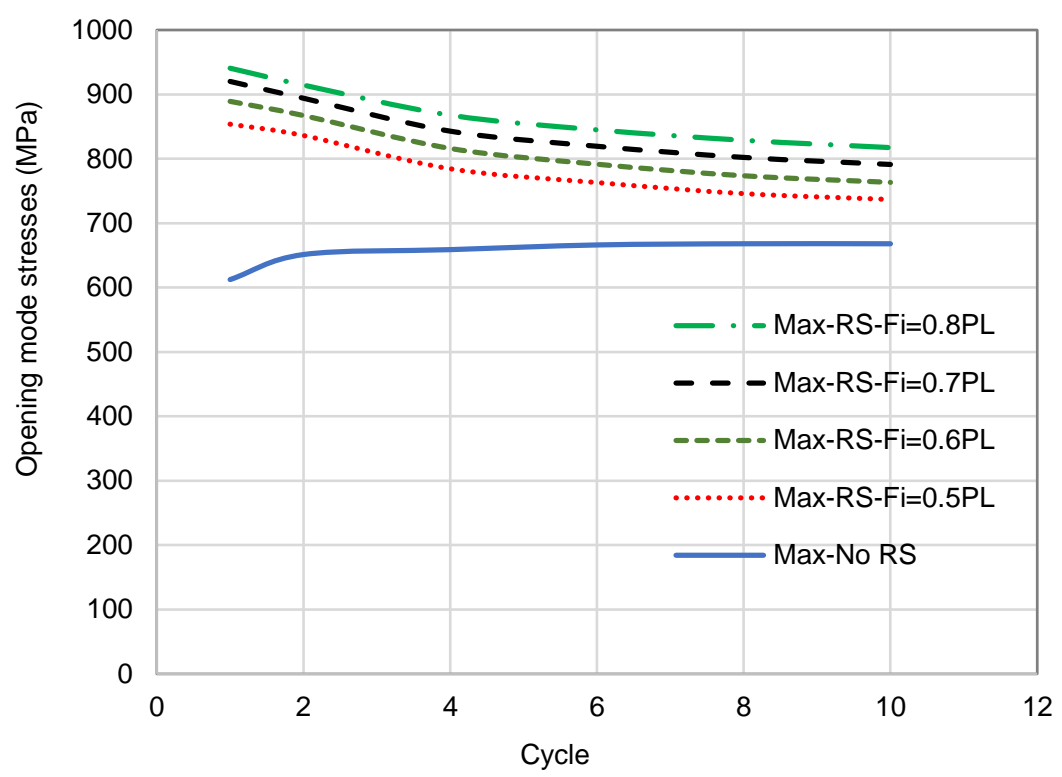

Figure 15. Opening mode stresses versus the cycles of loading $(\mathrm{Pmax}=4 \mathrm{kN}, \mathrm{R}=0.1)$

\section{Fatigue Crack Growth Rate}

The experimental diagram of the FCG rate versus the range of the $J$-integral for the sample without residual stresses is shown in Figure 16. Each point in the diagram is obtained in accordance with ASTM E1820 [33] witch expressed in Eq. (9). By fitting a curve over the data in Figure 16, the material-dependent parameters in Eq. (11) are expressed as follows:

$$
\frac{d a}{d N}=0.00156(\Delta J)^{1.193}
$$

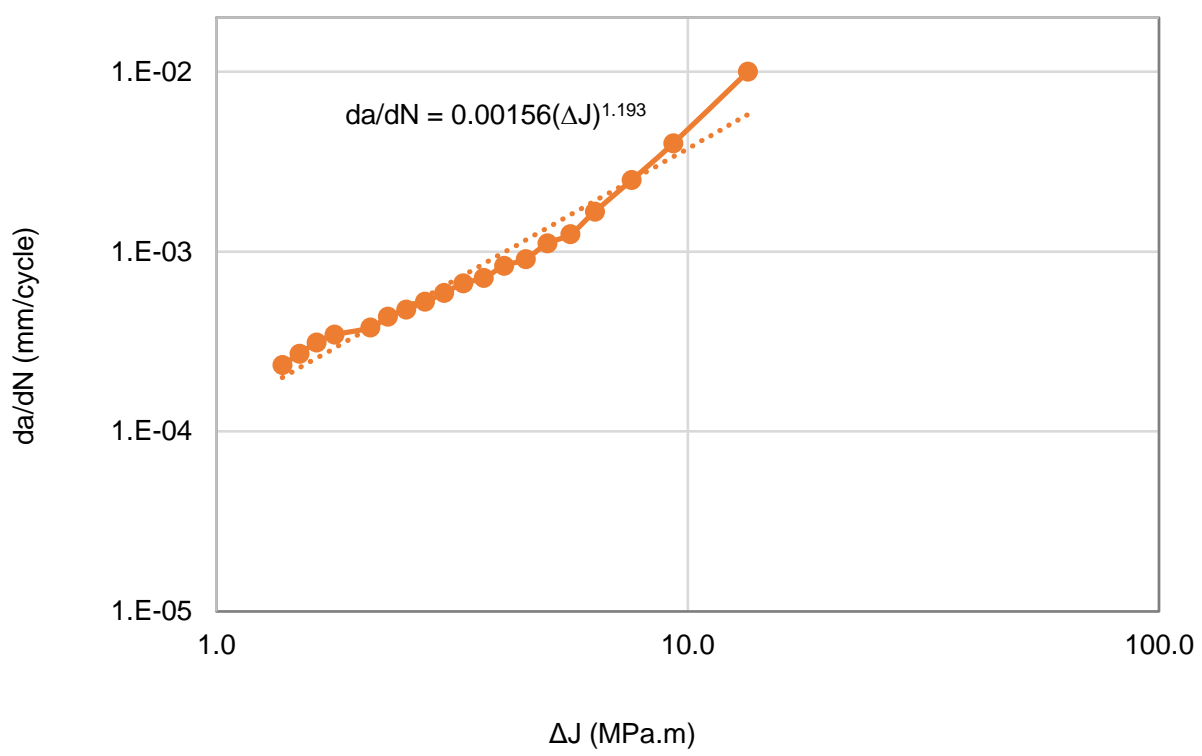

Figure 16. Fatigue crack growth rate versus the J-integral range in the specimen without residual stresses

The obtained crack growth rate $\mathrm{da} / \mathrm{dN}$ from the experiments, as a function of the stress intensity factor range $(\Delta K)$, is graphically presented in Figure 15. In the early stages of the crack growth, the crack growth rate in the specimen with residual stresses is faster than the rate in the specimens without residual stresses. 


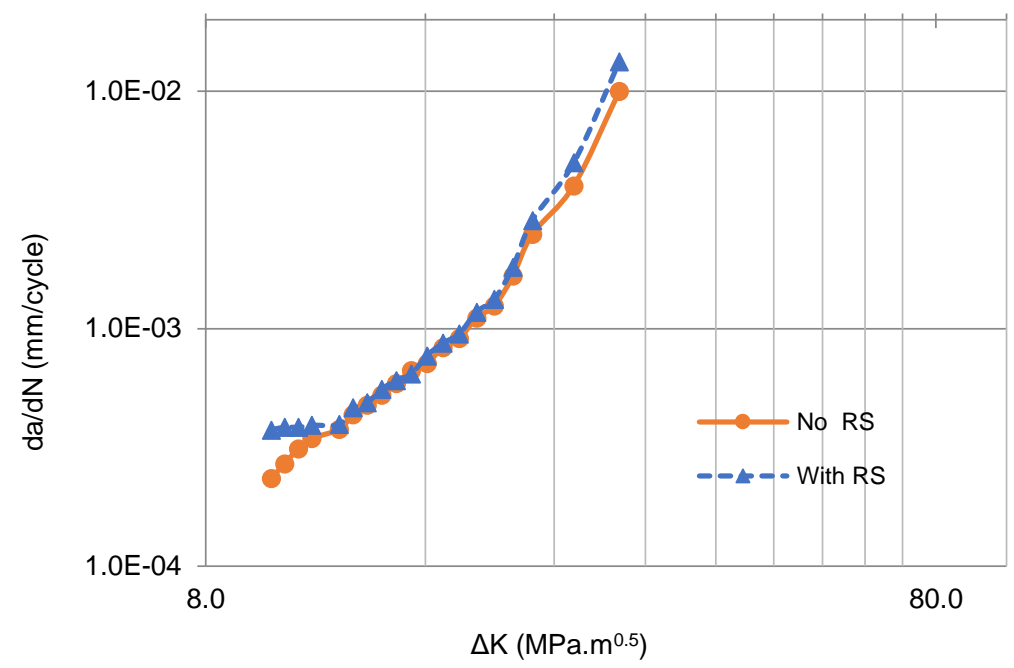

Figure 17. Fatigue crack growth rate versus $\Delta \mathrm{K}$ in logarithmic scale $(\Delta \mathrm{P}=$ constant $)$

The cyclic $J$-integral diagrams for different load ranges $(\Delta \mathrm{P})$ are presented as a function of the crack length (parameter $a$ that is shown in Figure 2) in Figure 16 and Figure 17. A good agreement is obtained between the FEM and experimental results.

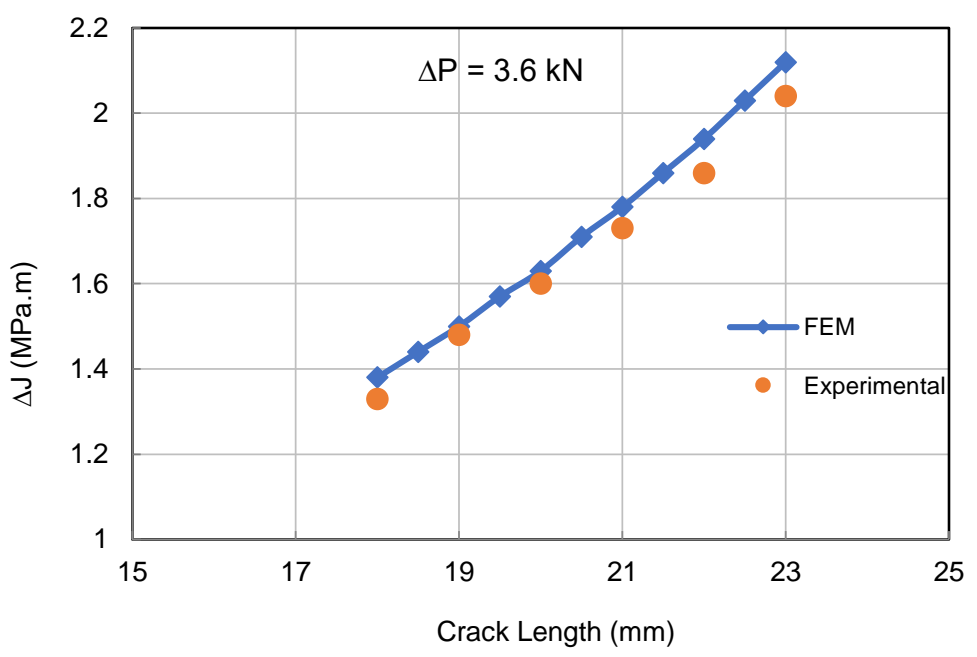

Figure 18. $\Delta \mathrm{J}$ in terms of the crack length from the experimental results and finite element method $(\Delta \mathrm{P}=3.6 \mathrm{kN})$

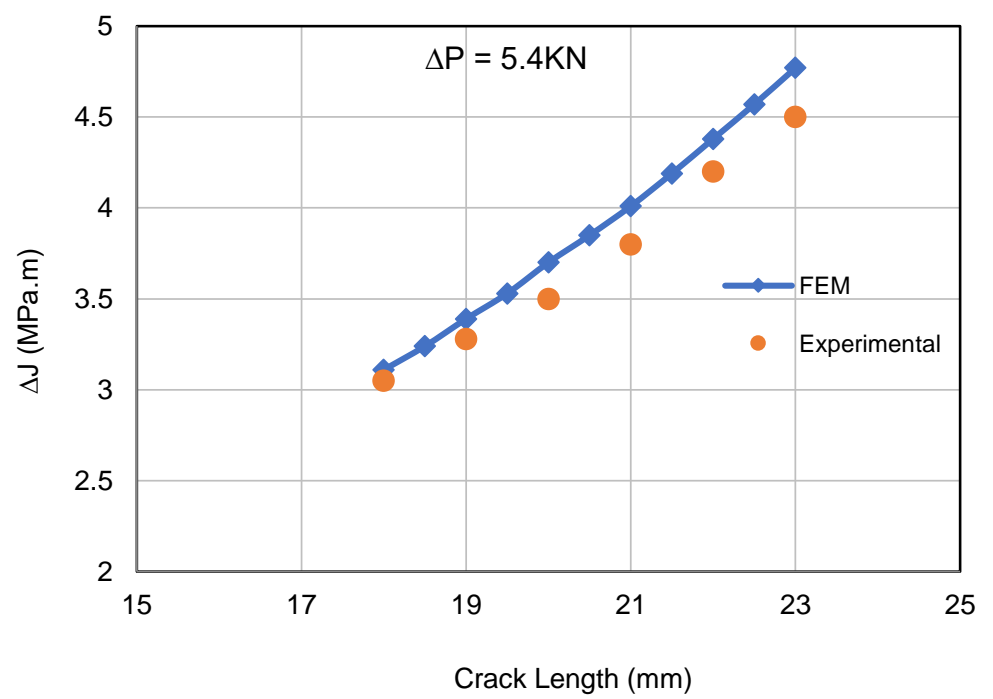

Figure 19. $\Delta \mathrm{J}$ in terms of the crack length from the experimental results and FEM $(\triangle \mathrm{P}=5.4 \mathrm{kN})$. 
The measured crack lengths versus the number of the cycles for four different cases; No RS (residual stresses), with RS neglecting relaxation, with RS considering relaxation and experimental results are illustrated in Figure 20. Under the same applied load, the life times of these cases are 59100, 53550, 49900 and 52200 cycles, respectively. It obviously indicates that tensile residual stresses decrease the fatigue life of the specimens. Furthermore, Neglecting the relaxation of the initial residual stresses leads to underestimate predictions the fatigue life of specimens.

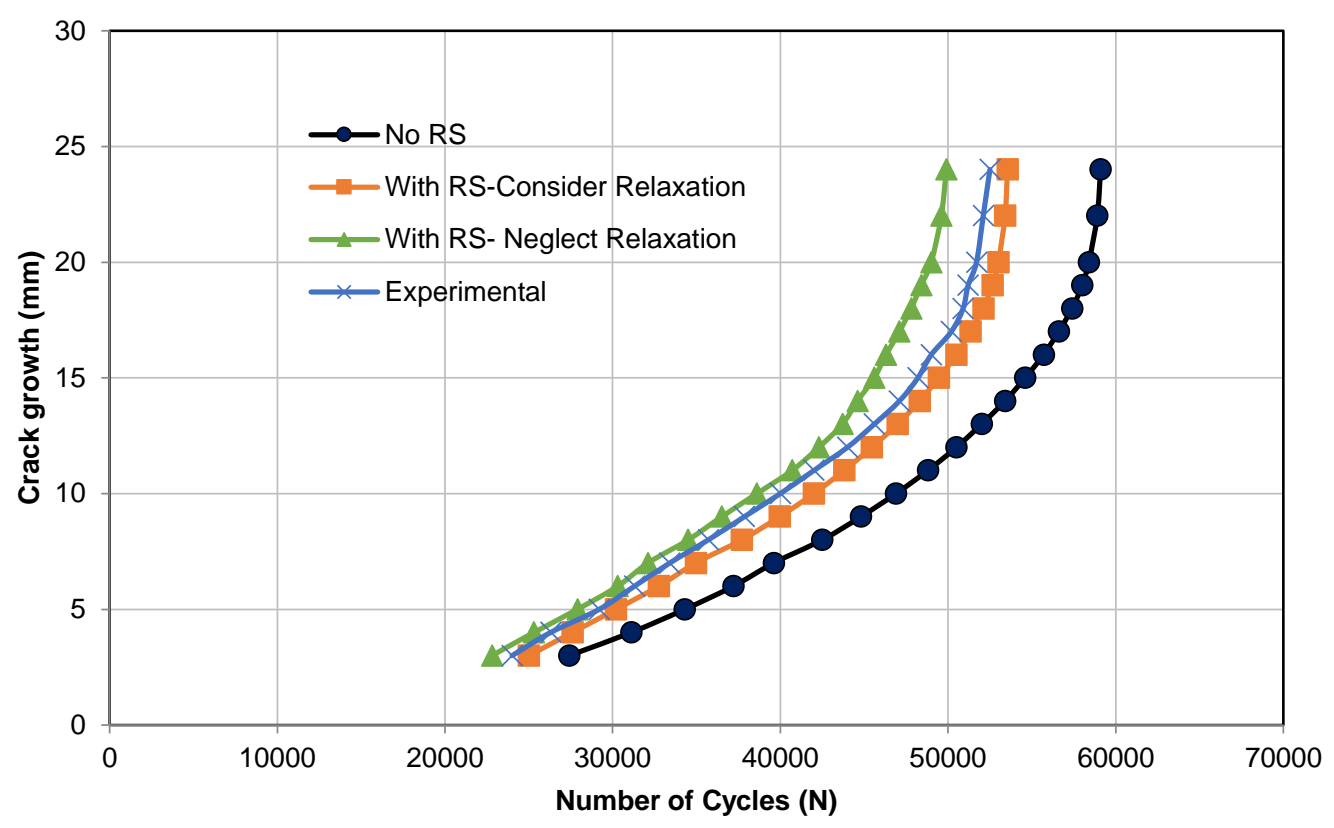

Figure 20. Crack growth versus the number of cycles

\section{CONCLUSION}

The present study addressed the effects of mechanical residual stresses on fatigue crack growth (FCG) behavior and life prediction methods. The redistribution of mechanical residual stresses during the fatigue, along with its effects on the fatigue life was studied as well. Furthermore, The changes of opening stresses during the fatigue loding were studied and the effects of stress ratio, load amplitude and initial residual stress level were evaluated. The FCG from a fatigue precracked under the influence of the mechanical residual stress field was evaluated using the finite element method (FEM). The FEM results were compared with the experimental data. It was observed that the mechanical residual stresses were relaxed during the FCG. The following findings may be concluded from this study:

- The initial mechanical residual stresses decrease rapidly after few fatigue cycles.

- The $J$-integral of the specimens with residual stresses decreases after the fatigue loading. The rate of the decrease depends on the loading amplitude.

- The load amplitude of the fatigue plays a great influence on the redistribution of residual stresses. The reduction percentage of initial residual stresses is higher at a higher load amplitude.

- In the case of negative stress ratio, fatigue loading would cause the generation of tensile residual stresses ahead of the crack tip.

- In the cases of positive stress ratio, the initial residual stresses are relaxed in a few cycles of loading. The greater values of stress ratio lead to more relaxation of initial residual stresses.

\section{DECLARATION OF COMPETING INTEREST}

The authors declare that they have no known competing financial interests or personal relationships that could have appeared to influence the work reported in this paper.

\section{REFERENCES}

[1] Z. Barsoum and I. Barsoum, "Residual stress effects on fatigue life of welded structures using LEFM," Eng. Fail. Anal., vol. 16, no. 1, pp. 449-467, 2009, doi: 10.1016/j.engfailanal.2008.06.017.

[2] W. V. Vaidya, P. Staron, and M. Horstmann, "Fatigue crack propagation into the residual stress field along and perpendicular to laser beam butt-weld in aluminium alloy AA6056," Fatigue Fract. Eng. Mater. Struct., vol. 35, no. 5, pp. 399-411, 2012, doi: 10.1111/j.1460-2695.2011.01631.x. 
[3] J. E. Larue and S. R. Daniewicz, "Predicting the effect of residual stress on fatigue crack growth," Int. J. Fatigue, vol. 29 , no. 3, pp. 508-515, 2007, doi: 10.1016/j.ijfatigue.2006.05.008.

[4] G. Servetti and X. Zhang, "Predicting fatigue crack growth rate in a welded butt joint: The role of effective R ratio in accounting for residual stress effect," Eng. Fract. Mech., vol. 76, no. 11, pp. 1589-1602, 2009, [Online]. Available: http://dx.doi.org/10.1016/j.engfracmech.2009.02.015.

[5] T. Ghidini and C. D. Donne, "Fatigue crack propagation assessment based on residual stresses obtained through cut-compliance technique," Fatigue Fract. Eng. Mater. Struct., vol. 30, no. 3, pp. 214-222, 2007, doi: 10.1111/j.1460-2695.2006.01059.x.

[6] G. Bussu and P. E. . Irving, "The role of residual stress and heat affected zone properties on fatigue crack propagation in friction stir welded 2024-T351 aluminum joints," Int. J. Fatigue, vol. 25, no. 1, pp. 77-88, 2003, doi: 10.1016/S0142-1123(02)000385 .

[7] A. Jacob, A. Mehmanparast, R. D’Urzo, and J. Kelleher, "Experimental and numerical investigation of residual stress effects on fatigue crack growth behaviour of S355 steel weldments," Int. J. Fatigue, vol. 128, p. 105196, 2019, doi: 10.1016/j.ijfatigue.2019.105196.

[8] A. Parker, "Stress intensity factors, crack profiles, and fatigue crack growth rates in residual stress fields," in Residual Stress Effects in Fatigue, ASTM International, 1982, pp. 13-19.

[9] W. Elber, "Fatigue crack closure under cyclic tension," Eng. Fract. Mech., vol. 2, no. 1, pp. 37-45, 1970, doi: 10.1016/00137944(70)90028-7.

[10] C. D. M. Liljedahl, M. L. Tan, O. Zanellato, S. Ganguly, M. E. Fitzpatrick, and L. Edwards, "Evolution of residual stresses with fatigue loading and subsequent crack growth in a welded aluminium alloy middle tension specimen," Eng. Fract. Mech., vol. 75, no. 13, pp. 3881-3894, 2008, doi: https://doi.org/10.1016/j.engfracmech.2008.02.005.

[11] G. H. Farrahi, G. H. Majzoobi, F. Hosseinzadeh, and S. M. Harati, "Experimental evaluation of the effect of residual stress field on crack growth behaviour in C(T) specimen," Eng. Fract. Mech., vol. 73, no. 13, pp. 1772-1782, 2006, doi: 10.1016/j.engfracmech.2006.03.004.

[12] Z. Semari et al., "Effect of residual stresses induced by cold expansion on the crack growth in 6082 aluminum alloy," Eng. Fract. Mech., vol. 99, pp. 159-168, 2013, doi: 10.1016/j.engfracmech.2012.12.003.

[13] M. H. Gozin and M. Aghaie-Khafri, "2D and 3D finite element analysis of crack growth under compressive residual stress field,” Int. J. Solids Struct., vol. 49, no. 23-24, pp. 3316-3322, 2012, doi: 10.1016/j.ijsolstr.2012.07.014.

[14] X. D. Ren et al., "The effects of residual stress on fatigue behavior and crack propagation from laser shock processing-worked hole," Mater. Des., vol. 44, pp. 149-154, 2013, doi: 10.1016/j.matdes.2012.07.024.

[15] O. S. Zaroog, A. Ali, B. B. Sahari, and R. Zahari, "Modeling of residual stress relaxation of fatigue in 2024-T351 aluminium alloy," Int. J. Fatigue, vol. 33, no. 2, pp. 279-285, 2011, doi: 10.1016/j.ijfatigue.2010.08.012.

[16] L. Zhu and M. P. Jia, "A new approach for the influence of residual stress on fatigue crack propagation," Results Phys., vol. 7, pp. 2204-2212, 2017, doi: 10.1016/j.rinp.2017.06.039.

[17] H. J. Yi and Y. J. Lee, "Numerical analysis of welding residual stress relaxation in high-strength multilayer weldment under fatigue loads," Metall. Mater. Trans. B Process Metall. Mater. Process. Sci., vol. 48, no. 4, pp. 2167-2175, 2017, doi: 10.1007/s11663-017-0958-0.

[18] C. H. Lee, K. H. Chang, and V. N. Van Do, "Finite element modeling of residual stress relaxation in steel butt welds under cyclic loading," Eng. Struct., vol. 103, pp. 63-71, 2015, doi: 10.1016/j.engstruct.2015.09.001.

[19] X. Xie, W. Jiang, Y. Luo, S. Xu, J. M. Gong, and S. T. Tu, "A model to predict the relaxation of weld residual stress by cyclic load: Experimental and finite element modeling," Int. J. Fatigue, vol. 95, pp. 293-301, 2017, doi: 10.1016/j.ijfatigue.2016.11.011.

[20] M. Farajian-Sohi, T. Nitschke-Pagel, and K. Dilger, "Residual stress relaxation of quasi-statically and cyclically-loaded steel welds," Weld. World, vol. 54, no. 1-2, pp. 49-60, 2010, doi: 10.1007/BF03263484.

[21] V. Dattoma, M. De Giorgi, and R. Nobile, "Numerical evaluation of residual stress relaxation by cyclic load," J. Strain Anal. Eng. Des., vol. 39, no. 6, pp. 663-672, 2004, doi: 10.1243/0309324042379248.

[22] W. Jiang, Y. Yu, W. Zhang, C. Xiao, and W. Woo, "Residual stress and stress fields change around fatigue crack tip: Neutron diffraction measurement and finite element modeling," Int. J. Press. Vessel. Pip., vol. 179, no. August 2019, p. 104024, 2020, doi: 10.1016/j.ijpvp.2019.104024.

[23] T. Yonezawa, H. Shimanuki, and T. Mori, "Influence of cyclic loading on the relaxation behavior of compressive residual stress induced by UIT,” Weld. World, vol. 64, no. 1, pp. 171-178, 2020, doi: 10.1007/s40194-019-00821-1.

[24] W. Zhong, Y. Ding, Y. Song, F. Geng, and Z. Wang, "Residual stress relaxation of drwds in osds under constant/variable amplitude cyclic loading," Appl. Sci., vol. 11, no. 1, pp. 1-23, 2021, doi: 10.3390/app11010253.

[25] Y. G. Dehkordi, A. P. Anaraki, and A. R. Shahani, "Comparative study of the effective parameters on residual stress relaxation in welded aluminum plates under cyclic loading," Mech. Ind., vol. 21, no. 5, 2020, doi: 10.1051/meca/2020061.

[26] “Abaqus, Dassault Systemes Simulia Corp., Providence, RI, USA.” Dassault Systemes Simulia Corp, Providence; RI, USA, 2014.

[27] A. Mirzaee-Sisan, "The influence of prior thermal and mechanical loading on fracture," University of Bristol, UK, 2005.

[28] Assessment of the Integrity of Structures Containing Deffects, 4th ed. Gloucester: British Energy, 2001.

[29] J. Wang and A. Mirzaee-Sisan, "The effect of plasticity on residual stress generation and redistribution in offshore pipelines," Int. J. Press. Vessel. Pip., vol. 159, pp. 101-110, 2018, doi: 10.1016/j.ijpvp.2017.11.011. 
[30] M. Turski, "High temperature creep cavitation cracking under the action of residual stress in 316H stainless steel," University of Manchester, UK, 2004.

[31] J. R. Rice, "A path independent integral and the approximate analysis of strain concentration by notches and cracks," J. Appl. Mech., vol. 35, no. 2, pp. 379-386, 1968, doi: 10.1115/1.3601206.

[32] Y. Lei, N. . O' Dowd, and G. . Webster, "Fracture mechanics analysis of a crack in a residual stress field," Int. J. Fract., vol. 106, no. 3, pp. 195-216, 2000, doi: 10.1023/A:1026574400858.

[33] ASTM-E1820-09, "Standard Test Method for Measurement of Fracture Toughness," ASTM Int., 2009, doi: 10.1520/E182009.2 .

[34] N. E. Dowling and J. A. Begley, "Fatigue crack growth during gross plasticity and the J-Integral," in Mechanics of Crack Growth, J. R. Rice and P. C. Paris, Eds. West Conshohocken, PA: ASTM International, 1976, pp. 82-103.

[35] ASTM Standard E647 - 13a, "Standard Test Method for Measurement of Fatigue Crack Growth Rates," Am. Soc. Test. Mater., pp. 1-50, 2014, doi: 10.1520/E0647-13A.2.

[36] M. R. Wenman, A. J. Price, A. Steuwer, P. R. Chard-Tuckey, and A. Crocombe, "Modelling and experimental characterisation of a residual stress field in a ferritic compact tension specimen," Int. J. Press. Vessel. Pip., vol. 86, no. 12, pp. 830-837, Dec. 2009, doi: 10.1016/j.ijpvp.2009.10.006.

[37] S. K. Paul, "Numerical models to determine the effect of soft and hard inclusions on different plastic zones of a fatigue crack in a C(T) specimen," Eng. Fract. Mech., vol. 159, pp. 90-97, 2016, doi: 10.1016/j.engfracmech.2016.03.028.

[38] S. K. Paul, "Effect of micro-cavities on different plastic zones at the fatigue crack tip of a compact tension specimen," Eng. Fract. Mech., vol. 158, pp. 13-22, 2016, doi: 10.1016/j.engfracmech.2016.02.041.

[39] S. K. Paul, "Numerical models of plastic zones and associated deformations for a stationary crack in a C(T) specimen loaded at different R-ratios," Theor. Appl. Fract. Mech., vol. 84, pp. 183-191, 2016, doi: 10.1016/j.tafmec.2015.10.008.

[40] T. L. Anderson, Fracture Mechanics: Fundamentals and Applications, Third Edit. CRC Press, 2005.

[41] A. J. McEvily, S. Ishihara, and Y. Mutoh, "On the number of overload-induced delay cycles as a function of thickness," Int. J. Fatigue, vol. 26, no. 12, pp. 1311-1319, 2004, doi: 10.1016/j.ijfatigue.2004.04.008.

[42] P. F. P. De Matos and D. Nowell, "Numerical simulation of plasticity-induced fatigue crack closure with emphasis on the crack growth scheme: 2D and 3D analyses," Eng. Fract. Mech., vol. 75, no. 8, pp. 2087-2114, 2008, doi: 10.1016/j.engfracmech.2007.10.017.

[43] K. Solanki, S. R. Daniewicz, and J. C. Newman, "Finite element modeling of plasticity-induced crack closure with emphasis on geometry and mesh refinement effects," Eng. Fract. Mech., vol. 70, no. 12, pp. 1475-1489, 2003, doi: https://doi.org/10.1016/S0013-7944(02)00168-6. 